Marquette University

e-Publications@Marquette

Biological Sciences Faculty Research and

Publications

Biological Sciences, Department of

4-1-2001

\title{
Treefall Gaps and the Maintenance of Species Diversity in a Tropical Forest
}

Stefan A. Schnitzer

Marquette University, stefan.schnitzer@marquette.edu

Walter P. Carson

University of Pittsburgh

Follow this and additional works at: https://epublications.marquette.edu/bio_fac

Part of the Biology Commons

\section{Recommended Citation}

Schnitzer, Stefan A. and Carson, Walter P., "Treefall Gaps and the Maintenance of Species Diversity in a Tropical Forest" (2001). Biological Sciences Faculty Research and Publications. 679.

https://epublications.marquette.edu/bio_fac/679 


\title{
TREEFALL GAPS AND THE MAINTENANCE OF SPECIES DIVERSITY IN A TROPICAL FOREST
}

\author{
Stefan A. Schnitzer ${ }^{1}$ And Walter P. Carson \\ Department of Biological Sciences, University of Pittsburgh, Pittsburgh, Pennsylvania 15260 USA
}

\begin{abstract}
The maintenance of species diversity by treefall gaps is a long-standing paradigm in forest ecology. Gaps are presumed to provide an environment in which tree species of differing competitive abilities partition heterogeneous resources. The empirical evidence to support this paradigm, however, remains scarce, and some recent studies even suggest that gaps do not maintain the diversity of shade-tolerant species. Although there is evidence that gaps maintain the diversity of pioneer trees, most of this evidence comes from studies that did not make comparisons between gaps and intact forest sites (controls). Further, nearly all studies on the maintenance of diversity by gaps have ignored lianas, an important component of both old-world and neotropical forests. We tested the hypothesis that treefall gaps maintain shade-tolerant tree, pioneer tree, and liana species diversity in an old-growth forest on Barro Colorado Island (BCI), Panama. We compared the density and species richness of these guilds between paired gap and non-gap sites on both a perarea and a per-individual (per capita) basis. We found no difference in shade-tolerant tree density and species richness between the gap and non-gap sites. Both pioneer tree and liana density and species richness, however, were significantly higher in the gap than in the nongap sites on both a per-area and a per-individual basis. These results suggest that gaps maintain liana species diversity and that this effect is not merely a consequence of increased density. Furthermore, our data confirm the long-held belief that gaps maintain pioneer tree species diversity. Because lianas and pioneer trees combined account for $\sim 43 \%$ of the woody plant species on BCI, and in other forests, our results are likely to be broadly applicable and suggest that gaps play a strong role in the maintenance of woody species diversity.
\end{abstract}

Key words: Barro Colorado Island, Panama; forest regeneration; gap hypothesis; lianas; Panama; pioneer trees; shade-tolerant trees; species diversity; treefall gaps; tropical forest.

\section{INTRODUCTION}

The maintenance of species diversity by treefall gaps remains a long-standing paradigm in forest ecology (Ricklefs 1977, Strong 1977, Hartshorn 1978, 1980, 1989, Whitmore 1978, 1989, Denslow 1980a, $b$, 1987, 1995, Runkle 1981, 1989, Orians 1982, Brokaw 1985, 1987, Brandani et al. 1988, Ashton 1989, Canham 1989, Clark et al. 1993, Brown 1996). One well documented mechanism by which gaps maintain diversity is by providing colonization sites for shade-intolerant, pioneer species in the community (Brokaw 1985, 1987, Whitmore 1989, Clark et al. 1993, Dalling et al. 1998; but see Uhl et al. 1988). Treefall gaps may also maintain the diversity of non-pioneer, shade-tolerant tree species if these species partition the heterogeneous resources, particularly light, within a gap (Ricklefs 1977, Strong 1977, Denslow 1980a, Orians 1982, Kobe 1999). Most studies, however, have failed to provide evidence for this latter mechanism (Hubbell and Foster 1986, Uhl et al. 1988, Lieberman et al. 1995, Whitmore and Brown 1996, Hubbell et al. 1999; but see Brandani

Manuscript received 18 November 1999; revised 17 February 2000; accepted 29 February 2000; final version received 5 April 2000.

${ }^{1}$ E-mail: Schnitze@ imap.pitt.edu et al. 1988). For example, after monitoring dipterocarp seedlings in gaps for more than six years, Whitmore and Brown (1996) concluded that within gaps there was "no evidence for fundamental niche differentiation." Further, Hubbell et al. (1999) concluded that gaps played a "relatively neutral role in maintaining species richness."

Treefall gaps have also been proposed to maintain diversity by increasing tree establishment, and thus density, which in turn can lead to higher tree species richness (Denslow 1995). This scenario, however, will not work if rapid thinning (mortality) following gap closure (e.g., Crow 1980, Brokaw 1985, Hubbell and Foster 1986) is random among species across the entire gap (i.e., no habitat specialization). In this case, the increase in diversity caused by gaps would simply be a transient effect of increased density and would disappear following thinning because density and diversity are typically positively correlated (Goldberg and Miller 1990, Denslow 1995, Gotelli and Graves 1996, Stevens and Carson 1999). Indeed, Hubbell et al. (1999) surveyed more than 1200 canopy gaps of varying sizes on Barro Colorado Island (BCI), Panama, and found no difference in tree species diversity between 2-yr-old gap and non-gap sites on a per individual (per capita) basis for saplings (1-4 cm dbh). Hubbell et al. 
(1999) concluded that the increased diversity found in gaps was only a transient effect of increased density. From this, Hubbell et al. (1999) argued that, with the exception of a small number of species (pioneer trees), gaps do not maintain tree diversity in tropical forests (see also Uhl et al. 1988). Furthermore, they argued that gaps do not affect sapling community composition, species richness, or relative species abundance, whether examined within gaps or over a landscape scale (Hubbell et al. 1999).

There have been a number of methodological problems with previous gap studies. First, as noted by Welden et al. (1991), only a few studies have actually compared gaps with non-gap control sites within intact forest. Additionally, with the exception of Hubbell et al. (1999), none of these studies examined the effect of gaps on a per individual basis, which is necessary to account for the effect of increased density on diversity. Overall, given the large number of papers proposing that gaps maintain diversity, we were surprised to find that few studies actually explicitly tested these hypotheses. Consequently, it may be premature to argue either that gaps maintain diversity, or conversely, have little effect on diversity in tropical forests.

In addition, a serious omission on the influence of gaps on species diversity is that nearly all of these studies have completely ignored lianas, an abundant growth form that reaches high diversity in tropical forests. Lianas typically compose upwards of one third of the woody species diversity and one quarter of the woody plant individual density in both old-world tropical and neotropical forests (Gentry 1982, 1983, 1991, Putz 1984, Uhl et al. 1988, Clark and Clark 1990; S. Schnitzer and W. Carson, unpublished data). Lianas are often arbitrarily excluded from studies because of the difficulty in identifying species in the field, distinguishing ramets from genets, and their erratic growth patterns (Putz 1980, 1984, Hegarty 1989, Clark and Clark 1990). Lianas, however, may be particularly abundant in gaps and important in gap-phase regeneration because they can reduce tree abundance and disproportionately impact the growth and mortality of tree species (Putz 1984, Schnitzer et al. 2000). Lianas may reach high abundance in gaps because, in contrast to trees, they have multiple ways to recruit into gaps. Unlike trees, lianas may be pulled into the gap by the treefall event or grow laterally into the gap from the surrounding intact forest (Peñulosa 1983, 1984, Putz 1984). Additionally, like trees, lianas can colonize gaps from the seed bank, seed rain, and from advance regeneration (Putz 1983, 1984, Putz and Chai 1987; S. Schnitzer and W. Carson, unpublished data). Further, lianas appear to persist in gaps for many years $(>13)$, long after the canopy of most gaps are closed (Schnitzer et al. 2000). Therefore, gaps may appear to maintain the diversity of lianas simply because gaps increase liana abundance for a relatively long period of time. However, to determine if gaps maintain the diversity of lianas independent of the effects of density, it is necessary to examine liana diversity on a per individual basis.

We tested the hypothesis that gaps maintain the diversity and density of lianas, pioneer trees, and shadetolerant trees. Unlike most previous studies, we compared the diversity of lianas and trees on both a per area and per individual basis between gaps and paired intact forest control sites. If gaps maintain diversity on a per area basis but not on a per individual basis, then the increase in diversity may be ephemeral and simply a by-product of increased density. On the other hand, if gaps maintain diversity independent of density, then another mechanism, such as resource partitioning, is likely to be involved.

\section{Methods \\ Study site}

We conducted this study in the 50-ha forest dynamics plot located in the old growth forest on BCI (see Hubbell and Foster 1983, 1986a). Barro Colorado Island is a 1600-ha forested island in central Panama that was isolated from the mainland in 1914 following the creation of Gatun Lake. The forest on BCI is a semideciduous, tropical moist forest with a 4-mo dry season from December to April. There is no evidence of largescale, human-induced disturbance for more than 500 $\mathrm{yr}$ in the old-growth portion of the forest on BCI. For more detailed information on the 50-ha forest dynamics plot or the formation, geology, climate, flora, and fauna of BCI, see Croat (1978), Hubbell and Foster (1983, 1986) Gentry (1990), and Leigh et al. (1996).

\section{Gap identification and definition}

We identified and defined gaps using canopy height data that have been collected annually since 1983 over a $5 \times 5 \mathrm{~m}$ grid throughout the entire 50-ha plot $(>20,000$ measurements per annum). Canopy height measurements were made using a range pole or range finder at the intersection of each $5 \times 5 \mathrm{~m}$ subplot (for details see Hubbell and Foster 1986a, Welden et al. 1991, Dalling et al. 1998, Hubbell et al. 1999). We defined a gap as a $25-75 \mathrm{~m}^{2}$ area that had a sustained canopy height of at least $20 \mathrm{~m}$ for two consecutive years and then dropped to a height of $5 \mathrm{~m}$ or less during the following year, the year of gap formation (methodologies follow those of Hubbell and Foster 1986, Welden et al. 1991, Dalling et al. 1998). For clarity, we will refer to the point where the canopy height census measurement was taken as the gap center. We acknowledge that we did not know the exact location of the gap center and gap edge; however, we used a sampling scheme that would include both of these zones (see Methods: Sampling procedures). Including both the gap center and edge may be crucial for the study of the maintenance of species diversity because the different microclimates in these zones may allow 
for an overall sustained increase in plant establishment and growth due to resource partitioning (Popma et al. 1988, Brown 1996). We excluded gaps that had failed to regenerate above $10 \mathrm{~m}$ in height because many of these recalcitrant, low-canopy gaps are often inundated by an exceptionally high number of lianas (see Schnitzer et al. 2000). Thus, our estimate of gaps promoting liana density and diversity is conservative because we excluded gaps that were completely dominated by lianas. We chose to use relatively small gaps, $\sim 25-75$ $\mathrm{m}^{2}$, because small gaps compose the majority $(>90 \%$ of 1284 gaps on BCI were $25-100 \mathrm{~m}^{2}$; Hubbell et al. 1999) of all gaps in both mature and secondary forests (Hubbell and Foster 1986, Sanford et al. 1986, Barton et al. 1989, Yavitt et al. 1995, Brokaw 1996, Lertzman et al. 1996, Dalling et al. 1998). In addition, small gaps accounted for approximately two-thirds of the total gap area on BCI (Hubbell et al. 1999). Thus, if treefall gaps are important to the maintenance of species diversity, then small gaps are likely to play a large role in this process.

For the set of gaps that met our criteria, we randomly selected 17 gaps, eight were from five to six years old and nine were from 10 to $11 \mathrm{yr}$ old. We visually surveyed all of the gaps to ensure that they were truly natural gaps, and not located over streams or trails (cf., Hubbell et al. 1999). We used gaps of two different time periods (five and $10 \mathrm{yr}$ old) so that we could distinguish any changes in gap density and diversity compared to intact forest over a relatively long period of time. Five-year-old gaps are likely to be higher in tree density and diversity than the intact forest (Brokaw 1985), while 10-yr-old gaps are likely to be more similar in density to the intact forest. Additionally, by analyzing gaps $10 \mathrm{yr}$ after gap formation, we could follow the dynamics much longer than did Hubbell et al. (1999). We paired each gap with an adjacent similar area of intact forest that had a canopy height above 20 $\mathrm{m}$ for at least $14 \mathrm{yr}$ and showed no evidence of recent disturbance. We made paired comparisons because of high variation in liana and tree abundance and diversity. The paired sites were separated by an average distance of $15 \mathrm{~m}$, with no pairs closer than $10 \mathrm{~m}$ or separated by more than $54 \mathrm{~m}$.

\section{Sampling procedures}

We divided each of the 17 gap and 17 non-gap sites into four equal quadrants and subsampled the density and diversity of the tree and liana individuals within each quadrant. We subsampled each quadrant using non-overlapping $1 \times 5 \mathrm{~m}$ stratified random transects that radiated out from the gap center to the edge of the quadrant at a randomly chosen compass direction. Because our gaps were smaller than $75 \mathrm{~m}^{2}$, the $1 \times 5 \mathrm{~m}$ transects would ultimately intersect both the gap center and the gap edge. Unlike Hubbell et al. (1999), who excluded lianas, we censused all woody saplings and lianas $(1-4 \mathrm{~cm} \mathrm{dbh})$ that broke the plane of each tran- sect at a height of $130 \mathrm{~cm}$ above the ground. We pooled the transect data for each site to get an estimate of liana and tree density and diversity per gap.

We took great care to include only liana and tree individuals (genets), and we did not count any individual more than once (our methods followed those of Putz 1984). We followed each liana down to the soil surface to verify that it was not connected above ground or obviously connected below ground to any other individual included in the census. We acknowledge, however, that on rare occasions we could not always distinguish a true individual from a vegetative offshoot because of current or previously existing underground connections. Although this could have resulted in a slight overestimation of liana abundance, it would have only affected liana species richness by underestimating the number of liana species in gaps following rarefaction analysis because the chance of selecting a new species is reduced with each additional ramet included in the rarefaction analysis (see Methods: Data analysis).

We identified all common lianas and trees in the field and had in our employ, Eduardo Sierra, a professional botanist with more than $12 \mathrm{yr}$ of taxonomic experience on BCI. For a small number of difficult species, we collected samples and identified them using herbarium specimens. We identified to species $>96 \%$ of the trees and $94 \%$ of the lianas.

\section{Data analysis}

We used a Fisher's exact test to compare liana and tree species richness and density (Sokal and Rohlf 1995, Weir 1996). Because we found no difference in liana or tree species richness between the two gap ages (see Results and discussion: Changes in diversity and density in gaps over time), we combined these data for the gap and non-gap comparisons. We divided the trees into pioneer and non-pioneer (shade-tolerant) guilds using the pioneer community described in Dalling et al. (1998), in which pioneers were defined as species requiring high light to regenerate. We compared the density and species richness of liana genets and both tree guilds in the gap and non-gap sites. To analyze species richness independent of density, we conducted a rarefaction simulation using EcoSim, a randomization software package (Gotelli and Entsminger 1997). We rarefied our data by separately pooling all of the individuals (genets) of each species of either liana, pioneer tree, or non-pioneer tree that were found in the gap sites, and then randomly selecting individuals from this gap community until we reached the density of the non-gap community of the growth form or guild being examined (either lianas, pioneer trees, and non-pioneer trees). We ran the rarefaction simulation for 1000 iterations for each of the three comparisons. After each iteration, we counted the number of species that were present in the gap and non-gap communities. We then compared the overall mean species richness of the gap 


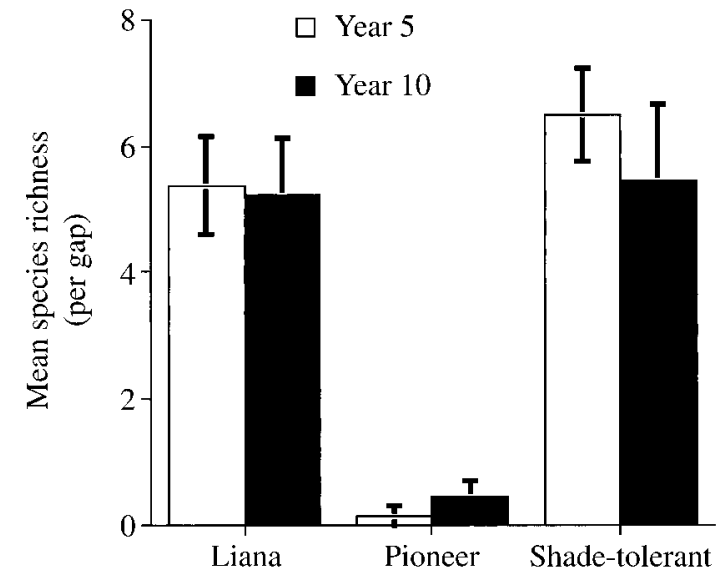

FIG. 1. Mean species richness for liana genets and for pioneer and shade-tolerant trees in 5- and 10-yr-old gaps on Barro Colorado Island, Panama. There was no significant difference between the different aged gaps for either lianas or either guild of tree. Error bars represent one standard error. An analysis of mean liana and tree density between the 5and 10-yr-old gaps yielded an almost identical relationship.

community to that of the non-gap community for the lianas, pioneer trees, and non-pioneer trees, independent of density (Gotelli and Graves 1996). We specifically chose the rarefaction technique designed for small sample sizes recommended by Gotelli and Graves (1996:27) that minimizes bias towards an overestimation of predicted species diversity sometimes associated with rarefaction techniques (Simberloff 1986, Gotelli and Graves 1996).

\section{Results And Discussion}

We identified a total of 51 tree species in the gap sites and 53 tree species in the non-gap sites. The two most common trees in each site were Hybanthus prunifolia and Faramea occidentalis. Hubbell and Foster (1992) also found that $H$. prunifolia and $F$. occidentalis were the two most common tree species on Barro Colorado Island. We sampled a total of 49 and 27 liana species in the gap and non-gap sites, respectively. The most common liana (only genets were counted) in both gap and non-gap sites was Maripa panamensis (see also Putz 1984). In gaps, Combretum laxum and Coccoloba parimensis were the next two most abundant liana species, while in the non-gap sites, Hiraea reclinata and Prionostemma aspera were the next two most abundant. Overall, the general patterns of liana genet abundance in this study paralleled those of Putz (1984) and a large liana demographic study on BCI $(n>20000$; S. Schnitzer and W. Carson, unpublished data).

\section{Changes in diversity and density in gaps over time}

We found no significant difference in liana or tree species richness or density between 5- and 10-yr-old gaps (Fig. 1). This suggests that any changes in the abundance or species richness of lianas and trees $(>1.3$ $\mathrm{m}$ tall and 1-4 $\mathrm{cm}$ diameter) following gap formation occurred before year five and remained fairly constant until year 10 .

\section{Shade-tolerant tree density and diversity}

Young gaps $(<2 \mathrm{yr}$ old) often have a higher density of shade-tolerant trees than do non-gap sites (Lawton and Putz 1988, Hubbell et al. 1999). Consequently, diversity may also be higher in young gaps because of the increase in stem density. For example, Hubbell et al. (1999) found that both density and diversity of shade-tolerant trees was higher in 2-yr-old gaps than in non-gap sites. They concluded, however, that this increase in diversity was caused by the increase in density, and that differences in diversity would disappear when these gaps thinned in subsequent years. Indeed, gaps typically begin to thin as soon as three years following gap formation (Brokaw 1985, Hubbell and Foster 1986). In slightly older gaps ( $>5$ yr old), we found no differences in either density or diversity of shadetolerant trees between gap and non-gap sites (Fig. 2; see also Uhl et al. 1988), presumably because some thinning may have occurred in the first three to five years. Thus, our findings are partly consistent with those of Uhl et al. (1988) and Hubbell et al. (1999); specifically, that gaps play a neutral role in maintaining diversity, but only for shade-tolerant trees.

\section{Pioneer tree density and diversity}

In contrast to shade-tolerant trees, pioneer tree density and species richness were significantly higher in gaps than in non-gap sites (Fig. 2). Indeed, we never found pioneers outside of gaps. These results are consistent with other reports suggesting that gaps maintain pioneer tree density and diversity (Brokaw 1985, 1987, Lawton and Putz 1988, Popma et al. 1988, Dalling et al. 1998), but only Lawton and Putz (1988) had appropriate intact forest control sites for comparison (Welden et al. 1991). Uhl et al. (1988), on the other hand, did not find that gaps increased the diversity of pioneers, because gaps remained dominated by shadetolerant tree species that were present as advance regeneration prior to gap formation. Still, our results confirm the long-held belief that gaps maintain pioneer tree species in the community.

\section{Liana density and diversity}

The density and species richness of liana genets were significantly higher in the gap than in the non-gap sites on both a per area (Fig. 2) and per individual basis. On a per area basis, liana genet species richness was higher in 15 of the 17 gaps than in the paired intact forest control sites, while in only one comparison was the non-gap liana species richness higher than that of the gap assemblage (one site had equal richness). The higher liana richness in gaps was not merely a function of an increase in density. The rarefaction analysis showed that liana genet species richness was higher in 
the gap than in the non-gap sites on a per individual basis $(P<0.05, n=88)$. Specifically, there were 33 \pm 2.45 (mean $\pm 1 \mathrm{SE}$ ) lianas in the gaps compared to 28 in the non-gap sites after we rarefied the number of lianas in gaps down to that of non-gaps (the standard error is zero for the non-gap sites because we combined all of the species in each of the 17 non-gap sites). This high per capita richness of liana genets suggests that gaps maintain liana diversity by a mechanism other than solely increasing density. We propose three possible hypotheses to explain why gaps have a higher species richness of lianas. The first two are both nichebased hypotheses, whereby lianas either partition the abundant and heterogeneous light resource in gaps (sensu, Ricklefs 1977, Denslow 1980a), or that lianas can be divided broadly into pioneer (gap specialists) and non-pioneer species. Although there is little evidence for the former hypothesis, several studies suggest that some or most lianas could be classified as early successional or gap dependent pioneers (Peñulosa 1984, Hegarty 1991, DeWalt et al. 2000). Putz (1984), on the other hand, classified only three of 65 liana species on BCI as early successional or gap-phase species, and we did not encounter any of these three species in our study.

A third hypothesis is that gaps provide a favorable site for liana colonization and persistence. We suggest that lianas have four ways to colonize gaps, whereas trees have only two. Similar to trees, lianas can colonize gaps from both seed and via advance regeneration. Lianas can compose from $18 \%$ to $31.5 \%$ of the advance regeneration $(<2 \mathrm{~m}$ tall $)$ under the intact canopy in tropical forests (Putz 1984, Putz and Chai 1987; S. Schnitzer and W. Carson, unpublished data). Additionally, unlike trees, lianas can colonize gaps as adults. Putz (1984) found that $\sim 90 \%$ of the adult lianas that are dragged into a gap with a treefall survive the treefall event. Lianas can also colonize gaps by growing laterally into, and subsequently rooting in gaps from adjacent areas under the intact canopy (Peñulosa 1983, 1984). The ability of a liana to colonize a gap from the intact forest greatly increases its rate of growth and chance of survival. Upon arrival in a gap, lianas vigorously produce new stems at a much more rapid rate than do trees (Appanah and Putz 1984, Putz 1984), which may promote greater survivorship. Because lianas can arrive in gaps in high numbers and survive in gaps for a long period of time $(>13 \mathrm{yr}$; Schnitzer et al. 2000), there will be a greater diversity of lianas in gaps than in the intact forest. Only further investigation on the ecology of lianas, however, will ultimately determine the percentage of liana species that require gaps in the same way that pioneer trees do or in other ways (e.g., enhancing survivorship and reproduction), whereby gaps ensure the persistence of liana species, maintaining them at a higher diversity throughout the forest.

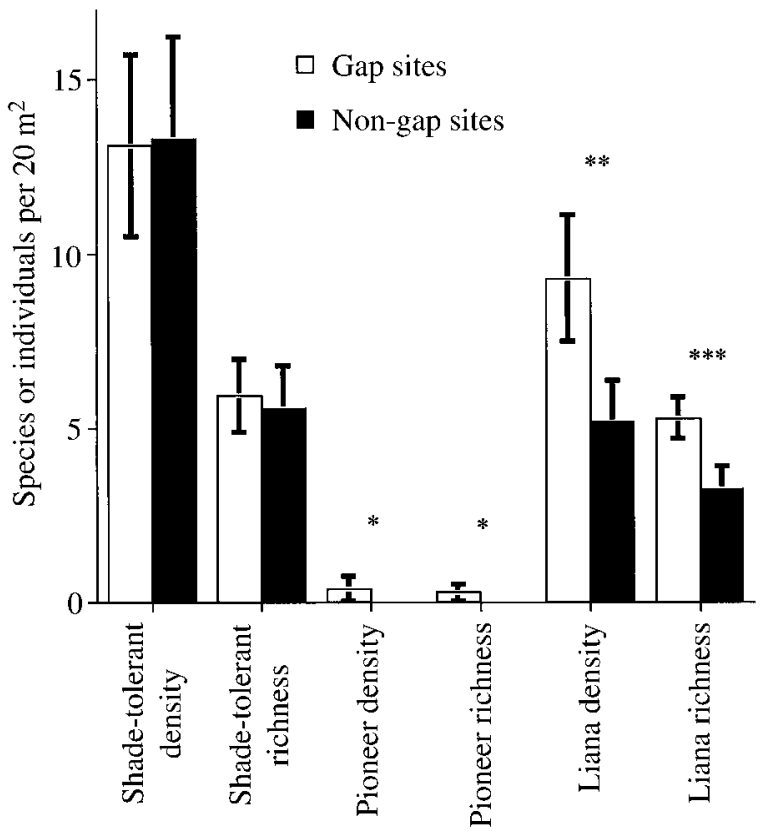

FIG. 2. Mean density and species richness in a $20-\mathrm{m}^{2}$ area in gap and non-gap sites on Barro Colorado Island, Panama. Analyses were conducted for shade-tolerant trees, pioneer trees, and liana genets. Overall, we sampled 230 and 226 trees, and 195 and 88 lianas $(n=17)$ in the gap and nongap sites, respectively. There was no significant difference in shade-tolerant tree density or species richness between the gap and non-gap sites $(P=0.17$ and $P=0.50$, respectively). For pioneer trees, gaps had a significantly higher density and species richness than did non-gap sites $(P=0.03$ and $P=$ 0.03 , respectively). Gaps also had a significantly higher liana genet density and species richness than did non-gap sites $(P$ $=0.01$ and $P=0.0003$, respectively). Although the variance appears to be high around the mean liana density and diversity of the gap and non-gap sites, we used a paired design to reduce this variability. Asterisks represent a significant difference between each paired gap and non-gap site. Error bars represent one standard error.

\section{Do gaps maintain woody species diversity in tropical forests?}

Although gaps did not appear to increase shade-tolerant tree species diversity, both liana and pioneer tree species diversity were significantly higher in gaps than in non-gap sites. Because lianas and pioneer trees compose $\sim 28 \%$ and $15 \%$ of the woody flora on BCI, respectively (Hubbell et al. 1999; S. Schnitzer and W. Carson, unpublished data), combined they compose $\sim 43 \%$ of the woody species. Barro Colorado Island is not unique in its proportion of lianas and pioneers, and many forests have a similar or higher proportion (Gentry 1982, 1991, Putz and Chai 1987, Balée and Campbell 1990, Clark and Clark 1990, Gentry and Dodson 1987). Consequently, our results contrast with previous studies (Hubbell and Foster 1986, Uhl et al. 1988, Whitmore and Brown 1996, Hubbell et al. 1999) in that we demonstrate the strong role of gap dynamics in maintaining a large proportion of the woody species diversity on BCI. Furthermore, we suggest that gaps 
may play a similar role in maintaining woody species diversity in many tropical forests.

\section{ACKNOWLEDGMENTS}

We thank Eduardo Sierra and Osvaldo Calderon for assisting with liana identification and verifying liana vouchers. Saara DeWalt assisted with much of the field work. Rick Condit, Stephen Hubbell, Robin Foster, and the Center for Tropical Forest Science generously provided census and canopy height data. Comments by Rachel Collins, James Dalling, Saara DeWalt, Kyle Harms, Michael Huston, Egbert Leigh, Zachary Long, Chris Peterson, Jack Putz, Henry Stevens, Joseph Wright, and two anonymous reviewers significantly improved this manuscript. This research was made possible, in part, by a fellowship from The University of Pittsburgh, and generous grants from the Garden Club of Allegheny County, Sigma XI, the Andrew Mellon Foundation Research Enhancement Awards in Tropical Biology, and the National Science Foundation Grant \# DEB-95 27729. The Smithsonian Tropical Research Institution provided logistic support.

\section{Literature Cited}

Appanah, S., and F. E. Putz. 1984. Climber abundance in virgin dipterocarp forest and the effect of pre-felling climber cutting on logging damage. The Malaysian Forester 47: 335-342.

Ashton, P. S. 1989. Species richness in tropical forests. Pages 239-251 in L. B. Holm-Nielsen, I. C. Nielsen, and H. Balsev, editors. Tropical forests: botanical dynamics, speciation, and diversity. Academic Press, London, UK.

Balée, W., and D. G. Campbell. 1990. Evidence for the successional status of liana forest (Xingu river basin, Amazonia Brazil). Biotropica 22:36-47.

Barton, A. M., N. Fetcher, and S. Redhead. 1989. The relationship between treefall gap size and light flux in a Neotropical rain forest in Costa Rica. Journal of Tropical Ecology 5:437-439.

Brandani, A., G. S. Hartshorn, and G. H. Orians. 1988. Internal heterogeneity of gaps and species richness in Costa Rican tropical wet forest. Journal of Tropical Ecology 4: 99-119.

Brokaw, N. V. L. 1985. Gap-phase regeneration in a tropical forest. Ecology 66:682-687.

Brokaw, N. V. L. 1987. Gap-phase regeneration of three pioneer tree species in a tropical forest. Journal of Ecology 75:9-20.

Brokaw, N. V. L. 1996. Treefalls: frequency, timing, and consequences. Pages 101-108 in E. G. Leigh, A. S. Rand, and D. M. Windsor, editors. The ecology of a tropical forest: seasonal rhythms and long-term changes. Smithsonian Institution Press, Washington, D.C., USA.

Brown, N. 1996. A gradient of seedling growth from the centre of a tropical rain forest canopy gap. Forest Ecology and Management 82:239-244.

Canham, C. D. 1989. Different responses to gaps among shade-tolerant tree species. Ecology 70:548-550.

Clark, D. B., and D. A. Clark. 1990. Distribution and effects of tree growth of lianas and woody hemiepiphytes in a Costa Rican tropical wet forest. Journal of Tropical Ecology 6:321-331

Clark, D. B., D. A. Clark, and P. M. Rich. 1993. Comparative analysis of microhabitat utilization by saplings of nine tree species in neotropical rain forest. Biotropica 25:397-407.

Croat, T. B. 1978. Flora of Barro Colorado Island. Stanford University Press, Stanford, California, USA.

Crow, T. R. 1980. A rainforest chronicle: a 30-year record of change in structure and composition at El Verde, Puerto Rico. Biotropica 12:42-55.

Dalling, J. W., S. P. Hubbell, and K. Silvera. 1998. Seed dispersal, seedling establishment and gap partitioning among tropical pioneer trees. Journal of Ecology 86:674689.

Denslow, J. S. 1980a. Gap partitioning among tropical rainforest trees. Biotropica 12(Supplement):47-55.

Denslow, J. S. 1980b. Patterns of plant species diversity during succession under different disturbance regimes. Oecologia 46: $18-21$.

Denslow, J. S. 1987. Tropical rainforest gaps and tree species diversity. Annual Review of Ecology and Systematics 18: 431-451.

Denslow, J. S. 1995. Disturbance and diversity in tropical rain forests: the density effect. Ecological Applications 5: 962-968.

DeWalt, S. J., S. A. Schnitzer, and J. S. Denslow. 2000. Density and diversity of lianas along a chronosequence in a central Panamanian lowland forest. Journal of Tropical Ecology 16:1-19.

Gentry, A. H. 1982. Patterns of neotropical plant species diversity. Pages 1-84 in M. K. Hecht, B. Wallace, and G. T. Prance, editors. Evolutionary biology. Volume 15. Plenum Press, New York, New York, USA.

Gentry, A. H. 1983. Lianas and the "paradox" of contrasting latitudinal gradients in wood and litter production. Tropical Ecology 24:63-67.

Gentry, A. H. 1990. Four neotropical rainforests. Yale University Press, New Haven, Connecticut, USA.

Gentry, A. H. 1991. The distribution and evolution of climbing plants. Pages 3-49 in F. E. Putz and H. A. Mooney, editors. The biology of vines. Cambridge University Press, Cambridge, UK.

Gentry, A. H., and C. Dodson. 1987. Contribution of nontrees to species richness of a tropical rain forest. Biotropica 19: 149-156.

Goldberg, D. E., and T. E. Miller. 1990. Effects of different resource additions on species diversity in an annual plant community. Ecology 71:213-225.

Gotelli, N. J., and G. L. Entsminger. 1997. EcoSim: null models software for ecology. Version 1.0. Kesey-Bear, Burlington, Vermont, USA.

Gotelli, N. J., and G. R. Graves. 1996. Null models in ecology. Smithsonian Institution Press, Washington, D.C., USA.

Hartshorn, G. S. 1978. Tree falls and tropical forest dynamics. Pages 617-638 in P. B. Tomlinson and M. H. Zimmerson, editors. Tropical trees as living systems. Cambridge University Press, Cambridge, UK.

Hartshorn, G. S. 1980. Neotropical forest dynamics. Biotropica 12 (Supplement):23-30.

Hartshorn, G. S. 1989. Gap-phase dynamics and tropical tree species richness. Pages 65-73 in L. B. Holm-Nielsen, I. C. Nielsen, and H. Balsev, editors. Tropical forests: botanical dynamics, speciation, and diversity. Academic Press, London, UK.

Hegarty, E. E. 1989. The climbers-lianes and vines. Pages 339-353 in H. Lieth and M. J. A. Werger, editors. Ecosystems of the world 14B. Tropical rain forest ecosystems. Biogeographical and ecological studies. Elsevier, Amsterdam, The Netherlands.

Hegarty, E. E. 1991. Leaf litter production by lianes and trees in a sub-tropical Australian rain forest. Journal of Tropical Ecology 7:201-214.

Hubbell, S. P., and R. B. Foster. 1983. Diversity of canopy trees in a neotropical forest and implications for conservation. Pages 25-41 in S. L. Sutton, T. C. Whitmore, and A. C. Chadwick, editors. Tropical rain forest: ecology and management. Blackwell Scientific Publications, Oxford, UK.

Hubbell, S. P., and R. B. Foster. 1986. Canopy gaps and the dynamics of a neotropical forest. Pages 77-96 in M. J. 
Crawley, editor. Plant ecology. Blackwell Scientific Publications, Oxford, UK.

Hubbell, S. P., and R. B. Foster. 1992. Short-term dynamics of a neotropical forest: why ecological research matters to tropical conservation and management. Oikos 63:48-61.

Hubbell, S. P., R. B. Foster, S. T. O'Brian, K. E. Harms, R. Condit, B. Wechsler, S. J. Wright, and S. Loo de Lao. 1999 Light gap disturbances, recruitment limitation, and tree diversity in a neotropical forest. Science 283:554-557.

Kobe, R. K. 1999. Light gradient partitioning among tropical tree species through differential seedling mortality and growth. Ecology 80:187-201.

Lawton, R. O., and F. E. Putz. 1988. Natural disturbance and gap-phase regeneration in a wind-exposed tropical cloud forest. Ecology 69:764-777.

Leigh, E. G., A. S. Rand, and D. M. Windsor, editors. 1996. The ecology of a tropical forest: seasonal rhythms and long term changes. Smithsonian Institution Press, Washington, D.C., USA.

Lertzman, K. P., G. D. Sutherland, A. Inselberg, and S. C. Saunders. 1996. Canopy gaps and the landscape mosaic in a coastal temperate rain forest. Ecology 77:1254-1270.

Lieberman, M., D. Lieberman, R. Peralta, and G. S. Hartshorn. 1995. Canopy closure and the distribution of tropical forest tree species at La Selva, Costa Rica. Journal of Tropical Ecology 11:161-178.

Orians, G. H. 1982. The influence of tree-falls in tropical forests on tree species richness. Tropical Ecology 23:255279

Peñulosa, J. 1983. Shoot dynamics and adaptive morphology of Ipomoea phillomega (Vell.) House (Convolvulaceae), a tropical rainforest liana. Annals of Botany 52:737-754.

Peñulosa, J. 1984. Basal branching and vegetative spread in two tropical rain forest lianas. Biotropica 16:1-9.

Popma, J., F. Bongers, and M. Martinez-Ramos. 1988. Pioneer species distributions in treefall gaps in Neotropical rain forest: a gap definition and its consequences. Journal of Tropical Ecology 4:77-88.

Putz, F. E. 1980. Lianas vs. Trees. Biotropica 12:224-225.

Putz, F. E. 1983. Liana biomass and leaf area of a "tierra firme" forest in the Rio Negro Basin, Venezuela. Biotropica 15:185-189.

Putz, F. E. 1984. The natural history of lianas on Barro Colorado Island, Panama. Ecology 65:1713-1724.

Putz, F. E., and P. Chai 1987. Ecological studies of lianas in Lambir National Park, Sarawak, Malaysia. Journal of Ecology 75:523-531.

Ricklefs, R. E. 1977. Environmental heterogeneity and plant species diversity: a hypothesis. American Naturalist 111: 376-381.

Runkle, J. R. 1981. Gap regeneration in some old-growth forests of the eastern United States. Ecology 62:10411051.

Runkle, J. R. 1989. Synchrony of regeneration gaps, and latitudinal differences in tree species diversity. Ecology 70: 546-547.

Sanford, R. L., H. E. Braker, and G. S. Hartshorn. 1986 Canopy openings in a primary neotropical lowland forest. Journal of Tropical Ecology 2:277-282.

Schnitzer, S. A., J. W. Dalling, and W. P. Carson. 2000. The impact of lianas on tree regeneration in tropical forest canopy gaps: evidence for an alternative pathway of gap-phase regeneration. Journal of Ecology 88:655-666.

Simberloff, D. 1986. Are we on the verge of a mass extinction in tropical rain forests? Pages 165-180 in D. K. Elliott, editor. Dynamics of Extinction. John Wiley \& Sons, New York, New York, USA.

Sokal, R. R., and F. J. Rohlf. 1995. Biometry. W.H. Freeman, New York, New York, USA.

Stevens, M. H. H., and W. P. Carson. 1999. Plant density determines species richness along an experimental fertility gradient. Ecology 80:455-465.

Strong, D. R. 1977. Epiphyte loads, tree falls, and perennial forest disruption: a mechanism for maintaining higher tree species richness in the tropics without animals. Journal of Biogeography 4:215-218.

Uhl, C., K. Clark, N. Dezzeo, and P. Maquino. 1988. Vegetation dynamics in Amazonian treefall gaps. Ecology 69: 751-763.

Weir, B. S. 1996. Genetic Data Analysis II. Sinauer Associates, Sunderland, Massachusetts, USA.

Welden, C. W., S. W. Hewett, S. P. Hubbell, and R. B. Foster. 1991. Sapling survival, growth, and recruitment: relationship to canopy height in a neotropical forest. Ecology 72: 35-50.

Whitmore, T. C. 1978. Gaps in the forest canopy. Pages 639655 in P. B. Tomlinson and M. H. Zimmerson, editors, Tropical trees as living systems. Cambridge University Press, Cambridge, UK.

Whitmore, T. C. 1989. Canopy gaps and the two major groups of forest trees. Ecology 70:536-538.

Whitmore, T. C., and N. D. Brown. 1996. Dipterocarp seedling growth in rain forest canopy gaps during six and a half years. Philosophical Transactions of the Royal Society of London 351:1195-1203.

Yavitt, J. B., J. J. Battles, G. E. Lang, and D. H. Knight 1995. The canopy gap regime in a secondary Neotropical forest in Panama. Journal of Tropical Ecology 11:391-402. 